\title{
Periprocedural Coagulation Status in Percutaneous Interventions
}

\author{
Soumil Singhal ${ }^{1}$ Mangerira Chinnappa Uthappa ${ }^{1}$ \\ ${ }^{1}$ Department of Intervention Radiology and Intervention Oncology, \\ BGS Gleneagles Global Hospital, Kengeri, Bangalore, India
}

Address for correspondence Soumil Singhal, MD, Department of Intervention Radiology and Intervention Oncology, BGS Gleneagles Global Hospital, 67, Uttarahalli Main Rd, Sunkalpalya, Kengeri, Bangalore 560060, India (e-mail: drsoumilsinghal75@gmail.com).
Abstract
Keywords
- hemostasis
- hemorrhage
- anticoagulants
- blood coagulation tests
- partial thromboplastin time
- prothrombin time

Hemostasis is a very elaborate process, and its knowledge is essential for every interventional radiologist. Abnormal coagulation parameters are associated with an increased risk of bleeding and require appropriate management. This review aims to briefly discuss the pathophysiology of hemostasis, the role of currently available pharmacological agents affecting hemostasis, and the management of hemostasis during various percutaneous interventional procedures. A preprocedure proforma, when used as a checklist, can reduce procedure-related complications.

\section{Introduction}

Hemostasis (from the Greek "haimatos" meaning blood and "stasis" meaning stop) is a complex physiological process first described as a cascade of several enzymes in the 1960s. ${ }^{1}$ Normal hemostasis involves four tightly integrated steps: (1) vasoconstriction, (2) platelet adhesion and activation, (3) coagulation cascade activation, and (4) permanent plug formation secondary to counterregulatory mechanism. ${ }^{2}$ The thrombosis-hemorrhage balance between the coagulation cascade and the fibrinolytic system is very crucial and is always kept in check in a physiologically normal individual. Because of this complex multistep process, coagulation dysfunction is not surprisingly uncommon.

Every interventional radiologist must possess a deep understanding of hemostasis as multiple factors may result in alterations of the coagulation parameters. Many percutaneous interventional procedures have an inherent, albeit to a varying degree, risk of vascular injury and subsequent bleeding. The assessment and management of bleeding may often be delayed if the bleeding occurs in the deep tissues. A proper understanding of the coagulation pathway and the effect of various pharmacological agents on hemostasis is required for periprocedure planning and management of these patients. This article summarizes the underlying pathophysiology of hemostasis, laboratory methods for evaluation of the coagulation system, the currently available anticoagulants and antiplatelet drugs, and risk assessment of various interventional procedures.

\section{Pathophysiology}

Hemostasis involves two main steps: (1) primary hemostasis and (2) secondary hemostasis. The initial plug formation mainly characterizes primary hemostasis. It is a multifactorial process with a complex relationship between the platelets, vessel wall, and adhesive proteins. Vascular injury induces reflexive vasoconstriction following which platelets adhere to the exposed subendothelial tissue through a bridge formed between the collagen-platelet surface glycoprotein (GP) IV and von Willebrand factor (vWF)-platelet surface GP Ib. Following adhesion, platelets get activated and facilitate further adhesion and aggregation through activation of several surface receptors and the secretion of $\alpha$-granules as well as other dense granules. Once formed, the platelet plug is further stabilized by insoluble fibrin that is generated by the coagulation pathway.

Secondary hemostasis involves two main pathways including an extrinsic path and an intrinsic path. It has been received

October 29, 2018

accepted after revision

May 27, 2019

published online

December 2, 2019
DOI https://doi.org/

$10.1055 / \mathrm{s}-0039-3401304$

ISSN 2457-0214.
C2019 by Indian Society of

Vascular and Interventional Radiology
License terms

()(1) $\Theta \circledast$ 
well understood by the cell-based model, which suggests that extrinsic path plays the primary role in fibrin clot formation and includes initiation, amplification, propagation, and stabilization. ${ }^{3}$ Injury to the blood vessel starts the initiation phase that is characterized by blood getting exposed to extravascular tissue, which is rich in a lipoprotein seen in the fibroblast, smooth muscle, and the leukocyte, which is known as tissue factor (TF). Once the TF is activated by blood, it binds and activates factor VII. Activated factor VII further activates both factors $\mathrm{X}$ and IX, and activated factor $\mathrm{X}$ activates factor $\mathrm{V}$ and they together convert prothrombin to thrombin. Thrombin accelerates platelet adhesion and aggregation along with activation of factors VIII, V, and XI. The propagation phase is characterized by further thrombin activation. Thrombin then converts fibrinogen to fibrin ( - Fig. 1).

Uncontrolled coagulation is prevented by downregulation of the coagulation cascade. Thrombomodulin, an endothelial protein, along with thrombin activates protein $C$, which along with a cofactor, protein $\mathrm{S}$, inactivates activated factors $\mathrm{V}$ and VIII. Antithrombin inactivates activated factors II, $\mathrm{X}, \mathrm{XI}$, and XII. TF pathway inhibitor also plays a significant role in downregulation. The fibrinolytic system is activated to prevent unnecessary clotting during wound healing. Plasminogen, which is a proenzyme, gets activated by tissue plasminogen activator (tPA) to form plasmin, which cleaves the fibrin clot. Urokinase acts through the urokinase-type plasminogen activator receptors to activate plasminogen causing fibrinolysis.

\section{Evaluation of Various Coagulation Parameters}

The various coagulation parameters that need to be evaluated before a percutaneous procedure include (1) platelet count, (2) prothrombin time (PT), (3) international normalized ratio

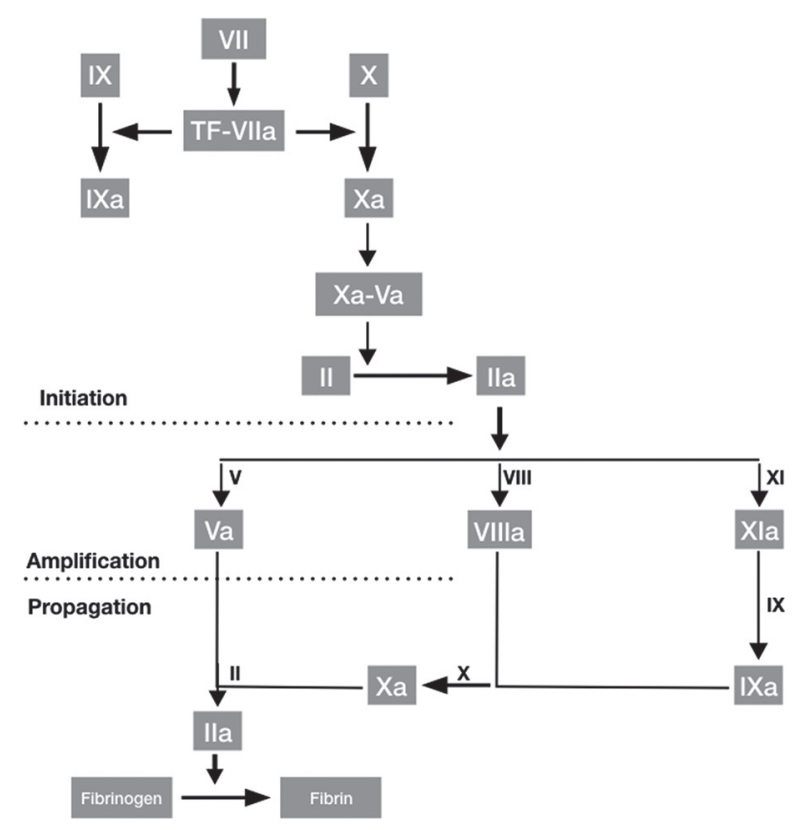

Fig. 1 Cell-based model of coagulation.
(INR), and (4) activated partial thromboplastin time (aPTT) (-Table 1). Correction of coagulation parameters may be required in a periprocedure setting based on the category of the procedure ( $\boldsymbol{-}$ Table $\mathbf{2}$ ).

\section{Platelet Count}

The fragmentation of megakaryocytes forms platelets. The life cycle of platelets lasts for 10 days. They play an essential role in the hemostasis by both creating a primary plug and providing a scaffold for clotting reaction. Platelet count refers to the number of platelets in circulation. The average adult range is 150,000 to 450,000 platelets per microliter of blood. Platelet count of less than $20,000 / \mu \mathrm{L}$ is associated with a high risk of spontaneous bleeding. ${ }^{4}$

A platelet transfusion may be required when there is either platelet dysfunction or reduction in number. Platelet transfusion is performed either in the form of a single donor unit or from a concentrated pool of four to eight donors. ${ }^{5} \mathrm{~A}$ single donor unit corrects platelet count by around $30,000 / \mu \mathrm{L}$, whereas a random donor unit corrects by around 5,000 to $10,000 / \mu \mathrm{L}$. Post transfusion, a repeat platelet count is necessary before the procedure. ${ }^{6}$ Repeated platelet transfusion reduces the effectiveness, warranting a more reasonable and calculated use along with the use of leucocyte-reduced platelets. ${ }^{7}$ In cases of complete refractiveness to the transfusion, human leucocyte antigen matching can be considered to plan transfusion. ${ }^{8}$

Platelet function defect can be either inherited or acquired; von Willebrand's disease is most common among the rare inherited platelet function defect. Acquired function defect is noted because of a medical condition or secondary to drug intake (e.g., aspirin). Platelet function analyzer is used to screen platelet dysfunction. Desmopressin, which is a synthetic analog of vasopressin hormone, has been found to increase the serum concentration of vWF, factor VIII, and tPA levels. ${ }^{9}$ It can be administered by various routes including subcutaneous, intranasal, or intravenous (IV), with IV being the route of choice. It is administered at $0.3 \mu \mathrm{g} / \mathrm{kg}$, which is infused slowly over 30 minutes, with maximum drug effect at around 30 to 60 minutes. Multiple treatments can lead to tachyphylaxis. It is indicated in conditions such as liver disease, uremia, hemophilia, and von Willebrand's disease. ${ }^{10}$

Table 1 Coagulation parameters and factors affecting them

\begin{tabular}{|l|l|l|}
\hline Test & Normal range & When to check? \\
\hline Platelet count & $150,000-450,000 / \mathrm{L}$ & Thrombocytopenia \\
\hline PT/INR & $0.9-1.1$ & $\begin{array}{l}\text { Liver disease } \\
\text { oral anticoagulant } \\
\text { therapy }\end{array}$ \\
\hline aPTT & $25-35 \mathrm{~s}$ & $\begin{array}{l}\text { Von Willebrand's } \\
\text { disease } \\
\text { Factor VIII, IX, or XI } \\
\text { deficiency } \\
\text { Intravenous heparin } \\
\text { therapy }\end{array}$ \\
\hline
\end{tabular}

Abbreviations: aPTT, activated partial thromboplastin time; PT/INR, prothrombin time/international normalized ratio. 
Table 2 Adaptation of Society of Interventional Radiology/Cardiovascular and Interventional Radiological Society of Europe consensus guidelines on periprocedural hematological management of image-guided procedures according to the category of bleeding risk ${ }^{22}$

\begin{tabular}{|c|c|c|c|}
\hline & Category I & Category II & Category III \\
\hline Nonvascular & $\begin{array}{l}\text { Thoracentesis } \\
\text { Paracentesis } \\
\text { Superficial aspiration or biopsy from } \\
\text { thyroid, superficial } \\
\text { lymph node } \\
\text { Superficial abscess drainage } \\
\text { All drainage catheter exchange }\end{array}$ & $\begin{array}{l}\text { Lung biopsy } \\
\text { Transabdominal liver biopsy } \\
\text { Percutaneous cholecystostomy } \\
\text { Intra-abdominal, chest wall, or } \\
\text { retroperitoneal abscess } \\
\text { drainage or biopsy } \\
\text { Gastrostomy tube } \\
\text { Radiofrequency ablation (easy } \\
\text { access) } \\
\text { Spine procedures (vertebroplasty, } \\
\text { kyphoplasty, lumbar } \\
\text { puncture, epidural injection, } \\
\text { facet block }\end{array}$ & $\begin{array}{l}\text { Biliary interventions } \\
\text { Renal biopsy } \\
\text { Nephrostomy tube placement } \\
\text { Difficult area: radiofrequency } \\
\text { ablation }\end{array}$ \\
\hline Vascular & $\begin{array}{l}\text { PICC placement } \\
\text { Dialysis access interventions } \\
\text { Venography } \\
\text { IVC filter placement } \\
\text { Central line removal }\end{array}$ & $\begin{array}{l}\text { Tunneled central venous catheter } \\
\text { Subcutaneous port device } \\
\text { Arterial intervention (access size } \\
\text { up to } 7 \mathrm{~F} \text { ) } \\
\text { Chemoembolization } \\
\text { Uterine fibroid embolization } \\
\text { Venous interventions } \\
\text { Transjugular liver biopsy }\end{array}$ & TIPS \\
\hline $\begin{array}{l}\text { Routinely recommend- } \\
\text { ed laboratory testing }\end{array}$ & $\begin{array}{l}\text { INR }^{\mathrm{a}} \\
\mathrm{aPTT}^{\mathrm{b}}\end{array}$ & $\begin{array}{l}\text { INR } \\
\text { aPTT }^{\mathrm{b}}\end{array}$ & $\begin{array}{l}\text { INR } \\
\text { aPTT } \\
\text { Platelet count } \\
\text { Hematocrit }\end{array}$ \\
\hline Correction & $\begin{array}{l}\text { INR }>2.0 \text { : correct } \\
\text { Platelets count }<50,000 / \mu \mathrm{L} \text { : platelet } \\
\text { transfusion } \\
\text { Clopidogrel: withhold for } 5 \mathrm{~d} \text { before } \\
\text { procedure } \\
\text { Aspirin: do not withhold } \\
\text { LMWH: withhold one dose prior to } \\
\text { procedure }\end{array}$ & $\begin{array}{l}\text { INR: correct to }<1.5 \\
\text { Platelets count }<50,000 / \mu / \mathrm{L} \text { : } \\
\text { platelet transfusion } \\
\text { Clopidogrel: withhold for } 5 \mathrm{~d} \\
\text { before procedure } \\
\text { Aspirin: do not withhold } \\
\text { LMWH: withhold one dose prior } \\
\text { to procedure }\end{array}$ & $\begin{array}{l}\text { INR: Correct to }<1.5 \\
\text { aPTT: stop or reverse heparin for } \\
\text { values }>1.5 \text { times the control } \\
\text { value } \\
\text { Platelets count }<50,000 / \mu \mathrm{L} \text { : } \\
\text { platelet transfusion } \\
\text { Clopidogrel: withhold for } 5 \mathrm{~d} \\
\text { before procedure } \\
\text { Aspirin: withhold for } 5 \mathrm{~d} \text { before } \\
\text { procedure } \\
\text { LMWH: withhold two doses prior } \\
\text { to procedure }\end{array}$ \\
\hline
\end{tabular}

Abbreviations: aPTT, activated partial thromboplastin time; INR, international normalized ratio; IVC, inferior vena cava; LMWH, low molecular weight heparin; PICC, peripherally inserted central catheter; TIPS, transjugular intrahepatic portosystemic shunt.

aFor patients receiving warfarin anticoagulation for known or suspected liver disease

${ }^{\mathrm{b}}$ For patients receiving intravenous unfractionated heparin.

\section{Prothrombin Time/International Normalized Ratio}

In vitro evaluation of the extrinsic pathway and fibrinogen integrity and stability can be made using the PT. It is converted and reported as the INR. INR is calculated as (patient $\mathrm{PT} /$ control PT) ISI, where ISI is the international sensitivity index of the thromboplastin reagent used. INR is used as a standardized parameter for patients on anticoagulant therapy. PT in an average healthy human ranges from 11 to 14 seconds and can vary based on the reagent used for testing. ${ }^{11}$ INR in a healthy patient ranges from 0.9 to 1.1 . Prolonged PT and INR are seen when there are deranged factors responsible for extrinsic and common pathways including vitamin K deficiency, warfarin therapy, liver failure, malabsorption, malnutrition among some of the conditions.

Deranged INR is frequently noted in a periprocedure setting. The American College of Chest Physicians guidelines ${ }^{12}$ suggests that in case of an elective procedure, vitamin $\mathrm{K}$ antagonist anticoagulant should be stopped 5 days before the procedure to facilitate the reduction of therapeutic INR value to around 1.5. If the procedure is planned within 1 to 2 days, 1 to $2 \mathrm{mg}$ of oral vitamin $\mathrm{K}$ should be administered. In case of an urgent procedure (within 12 hours), 2.5 to $5 \mathrm{mg}$ of vitamin $\mathrm{K}$ should be administered either orally or intravenously. However, in case of an emergency, vitamin $\mathrm{K}$ is given in combination with 10 to $15 \mathrm{~mL} / \mathrm{kg}$ of fresh frozen plasma (FFP). ${ }^{13}$ FFP has a half-life of 4 to 6 hours and can be associated with transfusion-related complication including anaphylaxis, transfusion-induced acute lung injury, and urticaria. Newer agents such as prothrombin complex concentrates and recombinant factor VIla can be used for the rapid correction of altered INR.

Prothrombin complex concentrates are plasma products that are vitamin $\mathrm{K}$ related factors and are formed by viral modification. They are 25 times richer than the normal 
plasma and have a half-life of 24 to 32 hours. ${ }^{14}$ Recombinant factor VIIa is found to be efficacious for various bleeding disorders. ${ }^{15}$ It has a half-life ranging from 1.7 to 3.1 hours and is administered between $15 \mu \mathrm{g} / \mathrm{kg}$ to $90 \mu \mathrm{g} / \mathrm{kg}$.

\section{Activated Partial Thromboplastin Time}

Activated partial thromboplastin time is the time taken for clot formation after activation of the intrinsic pathway. aPTT in an average healthy human ranges from 25 to 23 seconds. Isolated deranged aPTT values can sometimes be seen, which may be normal on repeat testing..$^{16}$ Altered aPTT can occur because of intrinsic factor deficiency, vitamin K deficiency, heparin therapy, liver failure, and lupus anticoagulant. aPTT in patients on heparin therapy is maintained at 1.5 to 2.5 times the control value.

\section{Anticoagulants}

Anticoagulants inhibit the coagulation pathway and prevent normal clot formation. These include warfarin, heparin, factor Xa inhibitors, and direct thrombin inhibitors. A clear understanding of various anticoagulants, their mechanism of action (described in $\mathbf{- F i g . ~} \mathbf{2}$ ), and the antidote is needed in a periprocedure setting to reduce procedure-related complications ( - Table 3 ).

\section{Warfarin}

Warfarin is an oral anticoagulant that was first discovered in sweet clover. It competitively inhibits vitamin $\mathrm{K}$ epoxide reductase complex 1 , which prevents activation of vitamin $\mathrm{K}$ and hence antagonizes the production of clotting factors II, VII, IX, and X, protein C, and protein S. Warfarin has a mean half-life of around 40 hours. Its effect can be monitored by evaluating the INR. Phytonadione (vitamin K) is a reversal agent and can be administered orally or through

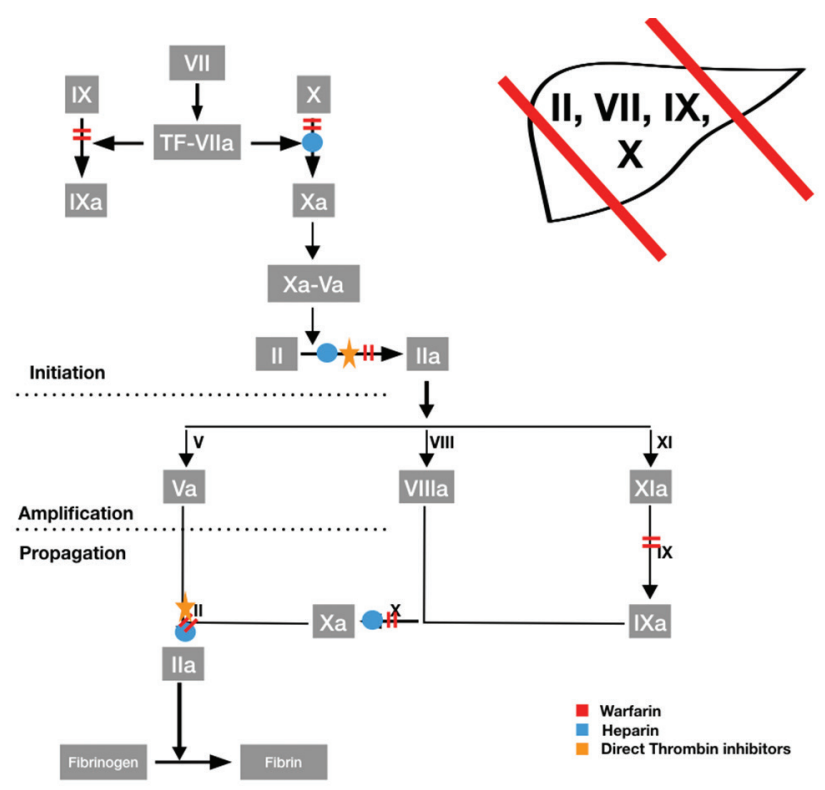

Fig. 2 Anticoagulants affecting various levels in the coagulation pathway. the subcutaneous or IV route. When given orally, it takes around 24 hours to act, and when given intravenously, it takes around 4 to 6 hours. Guidelines have been set by the American College of Chest Physicians in patients with a risk of bleeding. ${ }^{17}$ In adult patients posted for elective procedure, 2 to $5 \mathrm{mg}$ can be administered orally. The IV route is very effective and should be considered only during an emergency as it is associated with an anaphylactoid reaction. The subcutaneous route is not considered because of an erratic, unpredictable absorption.

\section{Heparin}

Heparin is a sulfated glycosaminoglycan that is produced by mast cells. It is available in two forms: (1) unfractionated form and (2) low molecular weight form.

\section{Unfractionated Heparin}

Unfractionated heparin has a mean molecular weight of $15,000 \mathrm{Da}$. It acts by potentiating the antithrombin effect, which inhibits factor Xa and thrombin by forming an equimolar stable complex which, in turn, inhibits coagulation. It is administered through the IV route. It has a half-life ranging from 23 minutes to 2.4 hours. $^{18}$ The therapeutic response is kept in check by assessing the aPTT. A note of the patient's platelet count has to be maintained to prevent heparininduced thrombocytopenia, which is characterized by a $50 \%$ reduction in platelet count 5 to 10 days following the initiation of heparin. Protamine sulfate is a reversal agent of choice in an emergency setting. It has a rapid mechanism of action (10 $\mathrm{min}$ ) and a half-life of 5 to 7 minutes. It is administered as a slow infusion dose calculated as $1 \mathrm{mg}$ of protamine per $100 \mathrm{U}$ of heparin. It is associated with complications such as anaphylactoid reaction, hypotension, and bradycardia. ${ }^{19-21}$

\section{Low Molecular Weight Heparin}

Low molecular weight heparin (LMWH) is a depolymerized form of heparin, with a mean molecular weight of 5,000 Da. Because of the smaller fragment size and lower binding property, it inhibits factor Xa only and has several advantages including predictable dose response, longer half-life, and less risk of heparin-induced thrombocytopenia. Dalteparin, enoxaparin, and tinzaparin are various types of LMWHs. LMWHs are mainly administered by the subcutaneous route. Protamine is less effective in the reversal of LMWH as it reverses the anti-factor IIa more than factor Xa activity, which is the primary target of LMWH. LMWH activity can be assessed by antifactor Xa activity; however, it is not well reported because of lack of standardization.

\section{Fondaparinux}

Fondaparinux is a selective indirect factor Xa inhibitor. It is a synthetic pentasaccharide, which is similar to LMWH in its mode of use. It has a longer half-life and a lesser rate of complications. It is administered subcutaneously at a daily dose of 1.5 to $10 \mathrm{mg}$ based on a patient's weight, renal function, and indication. It has a lower risk of heparin-induced thrombocytopenia. There is no specific reversal agent, but FFP or cryoprecipitate can be given to control bleeding. 
Table 3 Recommendations for the management of anticoagulants and reversal agent

\begin{tabular}{|c|c|c|c|c|}
\hline \multirow[t]{2}{*}{ Medication } & Category I & Category II & Category III & Reversal agent \\
\hline & \multicolumn{4}{|c|}{ Anticoagulant drugs } \\
\hline Warfarin & Withhold $5 \mathrm{~d}$ prior & $\begin{array}{l}\text { Withhold } 5 \mathrm{~d} \\
\text { prior }\end{array}$ & $\begin{array}{l}\text { Withhold } 5 \mathrm{~d} \\
\text { prior }\end{array}$ & $\begin{array}{l}\text { Vitamin } \mathrm{K} \\
\text { Fresh frozen plasma } \\
\text { Prothrombin complex concentrate }\end{array}$ \\
\hline LMWH & Withhold $12 \mathrm{~h}$ prior & $\begin{array}{l}\text { Withhold } 12 \mathrm{~h} \\
\text { prior }\end{array}$ & $\begin{array}{l}\text { Withhold } 12 \mathrm{~h} \\
\text { prior }\end{array}$ & Partial: protamine \\
\hline $\begin{array}{l}\text { Unfractionated heparin } \\
\text { (subcutaneous) }\end{array}$ & Withhold $4 \mathrm{~h}$ prior & $\begin{array}{l}\text { Withhold } 4 \mathrm{~h} \\
\text { prior }\end{array}$ & $\begin{array}{l}\text { Withhold } 6 \mathrm{~h} \\
\text { prior }\end{array}$ & Protamine \\
\hline Unfractionated heparin (IV) & Withhold $1 \mathrm{~h}$ prior & $\begin{array}{l}\text { Withhold } 4 \mathrm{~h} \\
\text { prior }\end{array}$ & $\begin{array}{l}\text { Withhold } 6 \mathrm{~h} \\
\text { prior }\end{array}$ & Protamine \\
\hline Fondaparinux & Withhold $24 \mathrm{~h}$ prior & $\begin{array}{l}\text { Withhold } 36 \mathrm{~h} \\
\text { prior }\end{array}$ & $\begin{array}{l}\text { Withhold } 48 \mathrm{~h} \\
\text { prior }\end{array}$ & None \\
\hline Dabigatran & Withhold 24 h prior & $\begin{array}{l}\text { Withhold } 48 \mathrm{~h} \\
\text { prior }\end{array}$ & $\begin{array}{l}\text { Withhold } 72 \mathrm{~h} \\
\text { prior }\end{array}$ & Idarucizumab \\
\hline Rivaroxaban & Withhold 24 h prior & $\begin{array}{l}\text { Withhold } 48 \mathrm{~h} \\
\text { prior }\end{array}$ & $\begin{array}{l}\text { Withhold } 48 \mathrm{~h} \\
\text { prior }\end{array}$ & Under trial \\
\hline Apixaban & Withhold 24 h prior & $\begin{array}{l}\text { Withhold } 48 \mathrm{~h} \\
\text { prior }\end{array}$ & $\begin{array}{l}\text { Withhold } 72 \mathrm{~h} \\
\text { prior }\end{array}$ & Under trial \\
\hline
\end{tabular}

Abbreviations: IV, intravenous; LMWH, low molecular weight heparin.

In patients undergoing category I or II procedures, one dose of LMWH has to be withheld, whereas in a category III procedure, patients with an aPTT value of more than 1.5 times the control value need to undergo a reversal and up to two doses of LMWH should be withheld before the procedure. ${ }^{22}$ Antifactor Xa assay can monitor patients on LMWH and fondaparinux. In a small series, protamine was found to be unable to stopping bleeding in two-third cases on LMWH. ${ }^{23}$ Factor VIIa has shown promising results in such a scenario and can be used as an antidote in patients on LMWH and fondaparinux. ${ }^{24}$

\section{Direct Thrombin Inhibitors}

The direct thrombin inhibitors act by directly inhibiting the activity of thrombin. They can be administered through the oral or parenteral route. They are either bivalent or univalent based on the sites blocked on thrombin. Bivalirudin, hirudin, lepirudin, and argatroban are few of the various inhibitors. The dose can be monitored by measuring the clotting time. They have a relatively short half-life (40-80 minutes); however; they do not have any proven reversal agent.

\section{Novel Oral Anticoagulants}

Novel oral anticoagulants (NOACs) are fast acting and have a specific target in the coagulation cascade as compared to their predecessors. These include rivaroxaban, edoxaban, betrixaban, apixaban, and dabigatran. Thrombin is targeted explicitly by dabigatran, and the rest target the activated factor $\mathrm{X} .^{25,26}$

Dabigatran acts by directly inhibiting both the free and bound forms of thrombin, which prevents further activation of fibrinogen. Dabigatran is unique as it has pH-dependent absorption due to which both proton pump inhibitors and antacids reduce its absorption. It has the longest halflife ranging from 12 to 17 hours. As the kidneys clear it, the pharmacokinetics is affected by kidney function. Dabigatran should be withheld for 3 days in patients with creatinine clearance less than $50 \mathrm{~mL} /$ minute and 5 days in patients with creatinine clearance less than $30 \mathrm{~mL} /$ minutes.

Rivaroxaban selectively and reversibly inhibits activated $\mathrm{Xa}$, which prevents platelet activation and clot formation. It has the shortest half-life and is cleared by the kidneys. The cytochrome P450 system metabolizes it. The anticoagulant effect is increased in patients on vitamin E, omega 3 fatty acid, erythromycin, and clarithromycin. Its effect is reduced in patients taking azole antibiotic or protease inhibitors. ${ }^{27-29}$

In patients planned for category I procedure, NOACs are not withheld before the procedure. In category II and III procedures, the drug needs to be held according to its half-life. Edoxaban and rivaroxaban should be withheld at least 24 hours before both category II and III interventions. Apixaban and dabigatran should be withheld 24 hours before category II and 48 before category III interventions.

As dabigatran has minimal protein-binding property, hemodialysis remains an option for reversal. Hemodialysis is not effective in patients using direct Xa inhibitors. Idarucizumab is an FDA (U.S. Food and Drug Administration) approved, target-specific, reversal agent against dabigatran. Idarucizumab is a monoclonal antibody with very high affinity to dabigatran. It is administered as two $2.5 \mathrm{-g}$ injections or $50-\mathrm{mL}$ IV infusion not more than 15 minutes apart. ${ }^{30-34}$ Andexanet alfa is an activated factor $\mathrm{X}$ inhibitor, which is still under trial. It is a recombinant human factor that acts as a decoy and inhibits both indirect and direct activated factor $\mathrm{X}$ inhibitors. Aripazine is a promising new agent under trial; it has shown potential reversal effect against several anticoagulants. It is a water-soluble molecule with many binding sites, which interact with various anticoagulants. It has a short half-life, no protein binding, rapid action, and no other drug interactions..$^{35}$ 


\section{Antiplatelets}

Antiplatelet agents act by inhibiting both platelet aggregation and platelet plug formation. These include aspirin, thienopyridines, nonsteroidal anti-inflammatory drugs (NSAIDs), and GP IIb/IIIa inhibitors ( - Table 4).

\section{Aspirin}

Aspirin or acetylsalicylic acid is a commonly used firstgeneration antiplatelet agent that has been used for more than a century in the prevention and treatment of various vascular diseases. Aspirin acts by inhibiting the platelet cyclooxygenase enzyme 1 , which inhibits platelet aggregation by reducing the production of prostaglandin precursors. It is metabolized into salicylic acid. It has a short half-life, with a peak antiplatelet effect by 40 to 60 minutes. Low-dose aspirin (75-162 $\mathrm{mg}$ ) is an effective long-term antiplatelet regimen. ${ }^{36}$ In case of an emergency, a high dose of aspirin (300-325 mg) is administered as a loading dose. The CURE (Clopidogrel in Unstable angina to prevent Recurrent Events) trial found an advantage when clopidogrel was given along with aspirin. ${ }^{37}$ Desmopressin acetate, which is a vasopressin antagonist, can be infused slowly (over more than 30 minutes) in 0.2 to 0.4 $\mu \mathrm{g} / \mathrm{kg}$ body weight concentration. Platelet infusion can also be used to reverse the aspirin's effect. Aspirin is not withheld in patients on low-dose aspirin, whereas patients who are on high-dose aspirin are advised to withhold the drug at least
5 days prior in case of category II and III interventions. It is resumed immediately postprocedure.

\section{Thienopyridines}

Thienopyridine group of drugs acts by inhibiting ADP-dependent platelet aggregation through the platelet P2Y12 receptor. They include clopidogrel (first generation), ticlopidine (second generation), and prasugrel (third generation).

Clopidogrel is an oral antiplatelet agent with a rapid onset of action and dose-dependent antiplatelet action. It is administered as $75 \mathrm{mg}$ per day, with an initial loading dose of 300 $\mathrm{mg}$. Both ticlopidine and prasugrel have a more rapid onset of action when compared with clopidogrel. No specific reversal agent is available; however, both platelet infusion and desmopressin can be helpful..$^{38}$ Clopidogrel is withheld five days before any category interventions. Ticlopidine and prasugrel are withheld 5 days before category I interventions and 7 days before category II and III interventions. ${ }^{39}$

\section{Nonsteroidal Anti-Inflammatory Drugs}

Nonsteroidal anti-inflammatory drugs are an antithrombotic agent with a reversal antiplatelet action. They act by inhibiting both cyclooxygenase enzyme 1 and 2 enzymes. NSAIDs are classified based on the different half-life into (1) short-acting (half-life of 2-6 hours), (2) intermediate-acting (half-life of 7-15 hours), and (3) long-acting (half-life more than 20 hours). There is no specific reversal agent.

Table 4 Recommendations for the management of antiplatelets and reversal agents

\begin{tabular}{|c|c|c|c|c|}
\hline Medication & Category I & Category II & Category III & Reversal agent \\
\hline & \multicolumn{4}{|c|}{ Antiplatelet drugs } \\
\hline \multicolumn{5}{|l|}{ Aspirin } \\
\hline Low dose & None & None & None & Desmopressin \\
\hline High dose & None & Withhold $5 \mathrm{~d}$ prior & Withhold $5 \mathrm{~d}$ prior & Demopressin, platelet, or both \\
\hline Clopidogrel & Withhold $5 \mathrm{~d}$ prior & Withhold $5 \mathrm{~d}$ prior & Withhold $5 \mathrm{~d}$ prior & Demopressin, platelet, or both \\
\hline Ticlopidine & Withhold $5 \mathrm{~d}$ prior & Withhold $5 \mathrm{~d}$ prior & Withhold $7 \mathrm{~d}$ prior & Demopressin, platelet, or both \\
\hline Prasugrel & Withhold $5 \mathrm{~d}$ prior & Withhold $5 \mathrm{~d}$ prior & Withhold $7 \mathrm{~d}$ prior & Demopressin, platelet, or both \\
\hline \multicolumn{5}{|l|}{ NSAIDs } \\
\hline \multicolumn{5}{|l|}{ Short acting } \\
\hline $\begin{array}{l}\text { Ibuprofen } \\
\text { Diclofenac } \\
\text { Ketoprofen } \\
\text { Indomethacin }\end{array}$ & Do not withhold & Do not withhold & Withhold 24 h prior & \multirow[t]{5}{*}{ None } \\
\hline \multicolumn{4}{|c|}{ Intermediate acting } & \\
\hline $\begin{array}{l}\text { Naproxen } \\
\text { Sulindac } \\
\text { Diflunisal } \\
\text { Celecoxib }\end{array}$ & Do not withhold & Do not withhold & Withhold 2-3 d prior & \\
\hline \multicolumn{4}{|l|}{ Long acting } & \\
\hline $\begin{array}{l}\text { Meloxicam } \\
\text { Nabumetone } \\
\text { Piroxicam }\end{array}$ & Do Not Withhold & Do Not Withhold & $\begin{array}{l}\text { Withhold } 10 \text { days } \\
\text { prior }\end{array}$ & \\
\hline Abciximab & Withhold 12-24 h prior & Withhold 24 h prior & Withhold 24 h prior & Platelet transfusion \\
\hline $\begin{array}{l}\text { Eptifibatide } \\
\text { Tirofiban }\end{array}$ & $\begin{array}{l}\text { Withhold immediately } \\
\text { before procedure }\end{array}$ & Withhold 4 h prior & Withhold $4 \mathrm{~h}$ prior & Demopressin, platelet, or both \\
\hline
\end{tabular}




\section{Glycoprotein Ilb/IIla Inhibitors}

Glycoprotein IIb/IIIa inhibitors prevent platelet aggregation by antagonizing the GP IIb/IIla integrin complex. It includes abciximab, eptifibatide, and tirofiban. These are fast-acting IV antiplatelet agents with a rapid onset of acting (1015 minutes after administration). Abciximab is a monoclonal antibody with the highest affinity toward the GP IIb/IIIa receptor lasting for 24 to 48 hours, whereas tirofiban and eptifibatide have an effect lasting for up to 4 hours postinfusion. No specific reversal agent is available; however, both platelet infusion (ineffective in tirofiban) and desmopressin can be helpful. ${ }^{40}$

\section{Chronic Liver Disease}

Patients who suffer from chronic liver disease have altered hemostatic mechanism; they are classically described to be in an autoanticoagulated state due to thrombocytopenia secondary to splenic sequestration and elevated INR due to hepatic dysfunction. These patients have a rebalanced coagulation system due to cirrhosis-related deficiency of both pro- and anticoagulants. ${ }^{41,42}$ The rebalanced state in these patients affects both primary and secondary hemostasis. Primary hemostasis is changed because of a decrease in the number of platelets; however; this effect is compensated by elevated levels of vWF and decrease in ADAMTS13 (a disintegrin and metalloproteinase with a thrombospondin type 1 motif, member 13). ${ }^{43,44} \mathrm{~A}$ study showed that a platelet count of around 55,000 allows normal clot formation. ${ }^{45}$ Secondary hemostasis is characterized by a reduction in liver-derived procoagulants, leading to an anticoagulated state; however, there is an associated compensatory decrease in anticoagulant levels (e.g., protein C, protein S, and antithrombin). ${ }^{46,47}$ The coagulation system remains in a steady state of balance, preventing any spontaneous bleeding episodes. An acute episode can tip this balance, leading to either bleeding or thrombosis. Platelet count, INR, and bleeding time has shown poor correlation, and hence tests such as thromboelastography, thromboelastometry, and sonorheometry are found to be more efficacious. ${ }^{48-50}$

\section{Categorization of Minimally Invasive Image- Guided Procedures}

A Delphi panel of experts categorized minimally invasive image-guided procedures due to the lack of randomized controlled studies or reliable recommendations on periprocedure management of patients undergoing interventional procedures. ${ }^{51}$ Representative procedures were categorized on the risk of bleed, and various recommendations were made (-Table 2). However, the committee believed that there could be variability within categories due to various patient-related factors including homeostatic abnormalities and preexisting comorbidities. The panel suggested that patient management should be tailor-made keeping in mind various patient-related factors. The Delphi recommendations are for elective cases with a single homeostatic defect. They did not address emergency interventions, multiple hemostatic abnormalities, and the use of closure devices. The Delphi consensus has some limitations that include the purpose and role of bleeding time, the role of recombinant factor VIIa, and the use of NSAIDs. ${ }^{52}$

\section{Periprocedure Proforma}

A periprocedure proforma (-Table 5) is a checklist tool that reduces procedure-related complications. The use of a well-devised proforma can improve patient outcomes.

Table 5 Periprocedure performa

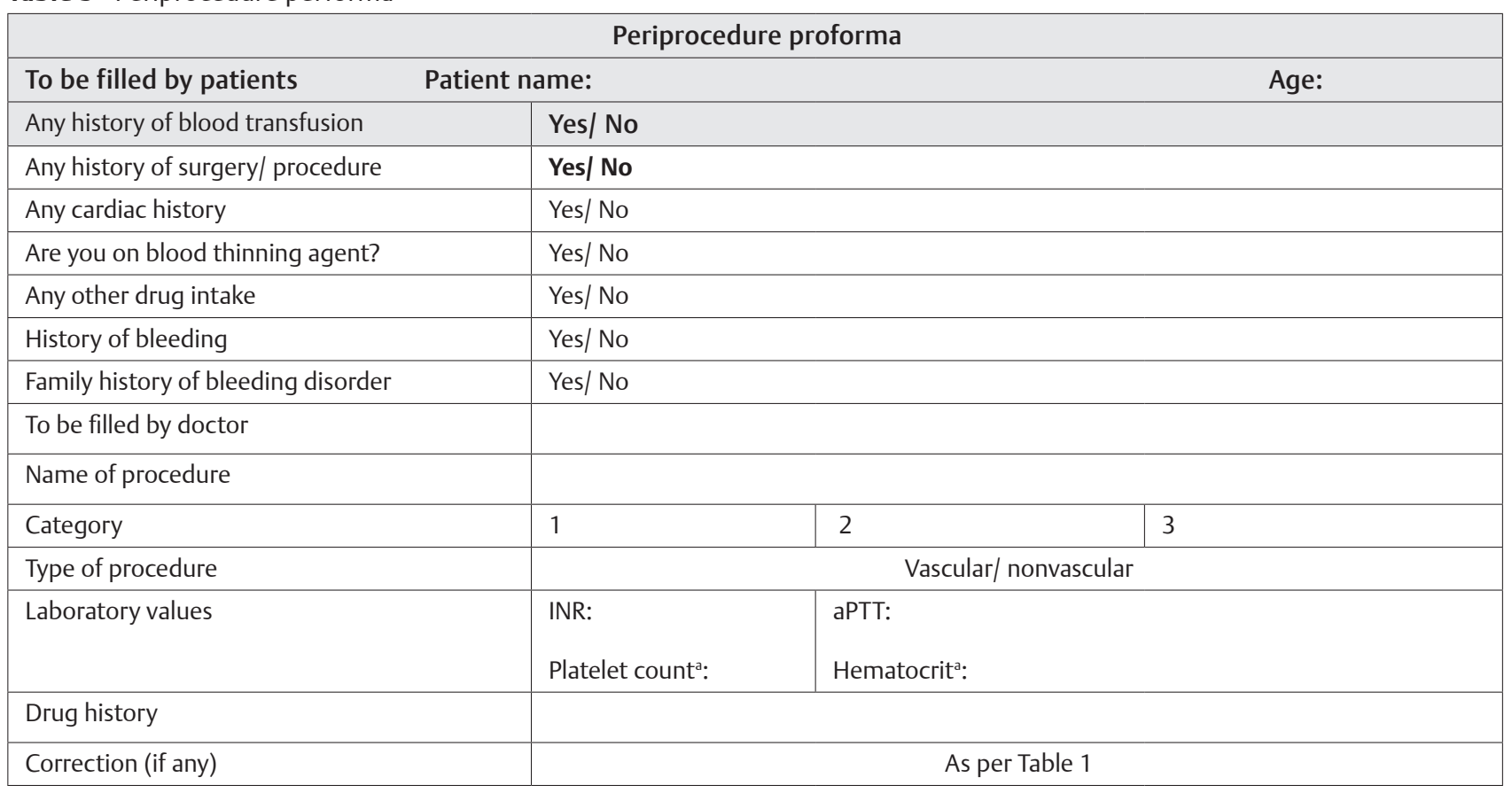

${ }^{a}$ Only for category III intervention. 
A well-devised periprocedure checklist includes two parts, one to be filled by the patient and the other to be filled by the physician. The questions to be answered by the patient consists of (1) prior history of surgery or any invasive procedures, (2) history of blood transfusion in the past, (3) cardiac history, (4) history of medication including blood thinning agents, (5) prior history of bleeding, and (6) any family history of bleeding disorder. The portion to be filled by the treating physician includes (1) procedure name, (2) category the procedure, (3) nature of the procedure, (4) laboratory parameters, and (5) patient drug intake history. Various checklists have been proposed in intervention radiology to improve patient safety and outcome. We recommend a preprocedure proforma of a checklist that can reduce procedure-related bleeding if executed efficiently.

\section{Conclusion}

Coagulation is a complicated process that requires thorough knowledge before performing any invasive procedure. Periprocedure protocol is essential for the planning and management of various coagulation defects. A welldevised proforma includes the procedure category, laboratory parameters, and correction (as needed) based on the precise knowledge of coagulation and the effect of anticoagulants. By including clinical parameters including the patient's history helps in the reduction of procedure-related complication.

\section{Conflicts of Interest}

None declared.

\section{References}

1 Achneck HE, Sileshi B, Parikh A, Milano CA, Welsby IJ, Lawson $\mathrm{JH}$. Pathophysiology of bleeding and clotting in the cardiac surgery patient: from vascular endothelium to circulatory assist device surface. Circulation 2010;122(20):2068-2077

2 Kumar V, Abbas AK, Fausto N, Aster JC. Hemodynamic disorders, thromboembolic disease and shock. In: Robbins and Cotran Pathologic Basis of Disease. 8th ed. Philadelphia, PA: Saunders Elsevier; 2010 118-120

3 Triplett DA. Coagulation and bleeding disorders: review and update. Clin Chem 2000;46(8 Pt 2) :1260-1269

4 Greinacher A, Selleng K. Thrombocytopenia in the intensive care unit patient. Hematology (Am Soc Hematol Educ Program) 2010;2010:135-143

5 O'Connell B, Lee EJ, Schiffer CA. The value of 10-minute posttransfusion platelet counts. Transfusion 1988;28(1):66-67

6 Schiffer CA, Anderson KC, Bennett CL, et al. American Society of Clinical Oncology. Platelet transfusion for patients with cancer: clinical practice guidelines of the American Society of Clinical Oncology. J Clin Oncol 2001;19(5):1519-1538

7 Trial to Reduce Alloimmunization to Platelets Study Group. Leukocyte reduction and ultraviolet B irradiation of platelets to prevent alloimmunization and refractoriness to platelet transfusions. N Engl J Med 1997;337(26):1861-1869

8 Heal JM, Blumberg N. Optimizing platelet transfusion therapy. Blood Rev 2004;18(3):149-165

9 Weiss HJ, Baumgartner HR, Tschopp TB, Turitto VT, Cohen D. Correction by factor VIII of the impaired platelet adhesion to subendothelium in von Willebrand disease. Blood 1978;51(2):267-279
10 Lethagen S. Desmopressin-a haemostatic drug: state-of-theart review. Eur J Anaesthesiol Suppl 1997;14:1-9

11 Hyers TM, Agnelli G, Hull RD, et al. Antithrombotic therapy for venous thromboembolic disease. Chest 2001;119 (1, Suppl):176S-193S

12 Douketis JD, Berger PB, Dunn AS, et al. . The perioperative management of antithrombotic therapy: American College of Chest Physicians Evidence-Based Clinical Practice Guidelines (8th Edition) Chest 2008;133(6 Suppl):299S-339S

13 O'Shaughnessy DF, Atterbury C, Bolton Maggs P, et al; British Committee for Standards in Haematology, Blood Transfusion Task Force. Guidelines for the use of fresh-frozen plasma, cryoprecipitate and cryosupernatant. $\mathrm{Br} \mathrm{J}$ Haematol 2004;126(1):11-28

14 Schulman S, Bijsterveld NR. Anticoagulants and their reversal. Transfus Med Rev 2007;21(1):37-48

15 Levi M, Peters M, Büller HR. Efficacy and safety of recombinant factor VIIa for treatment of severe bleeding: a systematic review. Crit Care Med 2005;33(4):883-890

16 Kitchens CS. To bleed or not to bleed? Is that the question for the PTT? J Thromb Haemost 2005;3(12):2607-2611

17 Ansell J, Hirsh J, Poller L, Bussey H, Jacobson A, Hylek E. The pharmacology and management of the vitamin K antagonists: the Seventh ACCP Conference on Antithrombotic and Thrombolytic Therapy. Chest 2004;126(3, Suppl):204S-233S

18 McAvoy TJ. The biologic half-life of heparin. Clin Pharmacol Ther 1979;25(3):372-379

19 Butterworth J, Lin YA, Prielipp R, Bennett J, James R. The pharmacokinetics and cardiovascular effects of a single intravenous dose of protamine in normal volunteers. Anesth Analg 2002;94(3):514-522

20 Brooks JC. Noncardiogenic pulmonary edema immediately following rapid protamine administration. Ann Pharmacother 1999;33(9):927-930

21 Wright SJ, Murray WB, Hampton WA, Hargovan H. Calculating the protamine-heparin reversal ratio: a pilot study investigating a new method. J Cardiothorac Vasc Anesth 1993;7(4):416-421

22 Malloy PC, Grassi CJ, Kundu S, et al; Standards of Practice Committee with Cardiovascular and Interventional Radiological Society of Europe (CIRSE) Endorsement. Consensus guidelines for periprocedural management of coagulation status and hemostasis risk in percutaneous image-guided interventions. J Vasc Interv Radiol 2009;20(7, Suppl):S240-S249

23 Massonnet-Castel S, Pelissier E, Bara L, et al. Partial reversal of low molecular weight heparin (PK 10169) anti-Xa activity by protamine sulfate: in vitro and in vivo study during cardiac surgery with extracorporeal circulation. Haemostasis 1986;16(2):139-146

24 Vavra KA, Lutz MF, Smythe MA. Recombinant factor VIIa to manage major bleeding from newer parenteral anticoagulants. Ann Pharmacother 2010;44(4):718-726

25 Eisert WG, Hauel N, Stangier J, Wienen W, Clemens A, van Ryn J. Dabigatran: an oral novel potent reversible nonpeptide inhibitor of thrombin. Arterioscler Thromb Vasc Biol 2010;30(10):1885-1889

26 Weitz JI. New oral anticoagulants in development. Thromb Haemost 2010;103(1):62-70

27 McMahon BJ, Kwaan HC. The new or non-vitamin K antagonist oral anticoagulants: what have we learned since their debut. Semin Thromb Hemost 2015;41(2):188-194

28 Palladino M, Merli G, Thomson L. Evaluation of the oral direct factor Xa inhibitor - betrixaban. Expert Opin Investig Drugs 2013;22(11):1465-1472

29 Liesenfeld KH, Lehr T, Dansirikul C, et al. Population pharmacokinetic analysis of the oral thrombin inhibitor dabigatran etexilate in patients with non-valvular atrial fibrillation from the RE-LY trial. J Thromb Haemost 2011;9(11):2168-2175 
30 Krishnamoorthy A, Sherwood MW, Lopes RD, Becker RC. The periprocedural management of novel oral anticoagulants in patients with nonvalvular atrial fibrillation: rationale and a summary of the available evidence from phase 3 clinical trials. Am Heart J 2015;169(3):315-322

31 Glund S, Moschetti V, Norris S, et al. A randomised study in healthy volunteers to investigate the safety, tolerability and pharmacokinetics of idarucizumab, a specific antidote to dabigatran. Thromb Haemost 2015;113(5):943-951

32 Glund S, Stangier J, Schmohl M, et al. Safety, tolerability, and efficacy of idarucizumab for the reversal of the anticoagulant effect of dabigatran in healthy male volunteers: a randomised, placebo-controlled, double-blind phase 1 trial. Lancet 2015;386(9994):680-690

33 Pollack CV, Jr. Reilly PA, Bernstein R, et al. Design and rationale for RE-VERSE AD: A phase 3 study of idarucizumab, a specific reversal agent for dabigatran. Thromb Haemost 2015;114(1):198-205

34 Pollack CV, Jr, Reilly PA, Eikelboom J, et al. Idarucizumab for dabigatran reversal. N Engl J Med 2015;373(6):511-520

35 Hollenbach S, Lu G, DeGuzman F. et al. Abstract 14657: Andexanet-alfa and PER977 (Arapazine) correct blood loss in a rabbit liver laceration model - only andexanet reverses markers of fXa-mediated anticoagulation. Circulation 2014:130 02:A14657

36 Antiplatelet Trialists' Collaboration. Collaborative meta-analysis of randomised trials of antiplatelet therapy for prevention of death, MI, and stroke in high-risk patients. BMJ 2002;324:71-86

37 Peters RJ, Mehta SR, Fox KA, et al; Clopidogrel in Unstable angina to prevent Recurrent Events (CURE) Trial Investigators. Effects of aspirin dose when used alone or in combination with clopidogrel in patients with acute coronary syndromes: observations from the Clopidogrel in Unstable angina to prevent Recurrent Events (CURE) study. Circulation 2003;108(14):1682-1687

38 Leithäuser B, Zielske D, Seyfert UT, Jung F. Effects of desmopressin on platelet membrane glycoproteins and platelet aggregation in volunteers on clopidogrel. Clin Hemorheol Microcirc 2008;39(1-4):293-302

39 Bijsterveld NR, Moons AH, Boekholdt SM, et al. Ability of recombinant factor VIIa to reverse the anticoagulant effect of the pentasaccharide fondaparinux in healthy volunteers. Circulation 2002;106(20):2550-2554
40 Reiter RA, Mayr F, Blazicek H, et al. Desmopressin antagonizes the in vitro platelet dysfunction induced by GPIIb/IIIa inhibitors and aspirin. Blood 2003;102(13):4594-4599

41 Tripodi A, Mannucci PM. The coagulopathy of chronic liver disease. N Engl J Med 2011;365(2):147-156

42 Northup PG, Sundaram V, Fallon MB, et al; Coagulation in Liver Disease Group. Hypercoagulation and thrombophilia in liver disease. J Thromb Haemost 2008;6(1):2-9

43 Lisman T, Bongers TN, Adelmeijer J, et al. Elevated levels of von Willebrand Factor in cirrhosis support platelet adhesion despite reduced functional capacity. Hepatology 2006;44(1):53-61

44 Mannucci PM, Canciani MT, Forza I, Lussana F, Lattuada A, Rossi E. Changes in health and disease of the metalloprotease that cleaves von Willebrand factor. Blood 2001;98(9):2730-2735

45 Tripodi A, Primignani M, Chantarangkul V, et al. Thrombin generation in patients with cirrhosis: the role of platelets. Hepatology 2006;44(2):440-445

46 Tripodi A, Primignani M, Chantarangkul V, et al. An imbalance of pro- vs anti-coagulation factors in plasma from patients with cirrhosis. Gastroenterology 2009;137(6):2105-2111

47 Tripodi A, Salerno F, Chantarangkul V, et al. Evidence of normal thrombin generation in cirrhosis despite abnormal conventional coagulation tests. Hepatology 2005;41(3):553-558

48 Salooja N, Perry DJ. Thrombelastography. Blood Coagul Fibrinolysis 2001;12(5):327-337

49 Tripodi A, Primignani M, Chantarangkul V, et al. The coagulopathy of cirrhosis assessed by thromboelastometry and its correlation with conventional coagulation parameters. Thromb Res 2009;124(1):132-136

50 Viola F, Kramer MD, Lawrence MB, Oberhauser JP, Walker WF. Sonorheometry: a noncontact method for the dynamic assessment of thrombosis. Ann Biomed Eng 2004;32(5):696-705

51 Fink A, Kosecoff J, Chassin M, Brook RH. Consensus methods: characteristics and guidelines for use. Am J Public Health 1984;74(9):979-983

52 Patel IJ, Davidson JC, Nikolic B, et al; Standards of Practice Committee, with Cardiovascular and Interventional Radiological Society of Europe (CIRSE) Endorsement; Standards of Practice Committee of the Society of Interventional Radiology. Addendum of newer anticoagulants to the SIR consensus guideline. J Vasc Interv Radiol 2013;24(5):641-645 